\title{
COMPARATIVE STUDY OF THE INHIBITIVE ACTION BETWEEN THE BITTER ORANGE LEAF EXTRACT AND ITS CHEMICAL CONSTITUENT LINALOOL ON THE MILD STEEL CORROSION IN HCL SOLUTION
}

\author{
Ashraf M. Abdel-Gaber ${ }^{\mathrm{a}, \mathrm{b}, *, \ldots, \text {, Khadija M. Hijazia }}{ }^{\mathrm{a}}$, Ghassan O. Younes ${ }^{\mathrm{a}}$ and Bilal Nsoulic \\ aDepartment of Chemistry, Faculty of Science, Beirut Arab University, Lebanon \\ ${ }^{b}$ Department of Chemistry, Faculty of Science, Alexandria University, Ibrahimia, P.O. Box 426, Alexandria 21321, Egypt \\ 'National Council for Scientific Research (CNRS), Lebanon
}

Recebido em 23/09/2016; aceito em 05/01/2017; publicado na web em 14/02/2017

\begin{abstract}
Bitter orange, Citrus Aurantium (CA), extract and one of its chemical constituents, Linalool, have been evaluated as a corrosion inhibitor for mild steel in $0.5 \mathrm{~mol} \mathrm{~L}^{-1}$ hydrochloric acid $(\mathrm{HCl})$ solution using potentiodynamic polarization, electrochemical impedance, Fourier transform infrared spectroscopy (FTIR), and atomic force spectroscopy (AFM) techniques. Functional groups of CA and Linalool were identified by FTIR spectroscopy. The Potentiodynamic polarization and electrochemical impedance studies showed that $\mathrm{CA}$ and Linalool act as mixed type inhibitors. The activation parameters showed that the corrosion inhibition takes place by spontaneous physical adsorption on the mild steel surface. Thermodynamic-kinetic model and Flory-Huggins isotherms were used to investigate the adsorption characteristics of CA and Linalool. The surface morphologies of mild steel specimens were studied using AFM, in which the surface roughness of the metal specimens on a micro scale was characterized.
\end{abstract}

Keywords: mild steel; electrochemical; corrosion; AFM; leaf extract; Linalool.

\section{INTRODUCTION}

The usage of steel in industrial sectors has created an extraordinary challenge for corrosion experts these days. Most acidic industrial applications such as acid descaling, oil-well acid in oil recovery and acid pickling use steel as their material. Corrosion is an electrochemical process by which the environment reacts with metallic surface forcing the metal to lose its material properties. ${ }^{1,2}$ It can cause catastrophic damage to the metal causing economic consequences. One of the practical methods used for metal protection against corrosion is the use of inhibitors. Numerous of organic compounds containing $\mathrm{N}, \mathrm{S}$ and $\mathrm{O}$ act as promising inhibitors. Nevertheless, most of these compounds are costly, as well as dangerous to living beings. ${ }^{3-5}$ Plant extracts have become important as environmentally acceptable and rich sources of active chemical ingredients. ${ }^{6}$ Studies showed that some of the plant extracts have inhibition efficiency exceed $90 \% .^{7-14}$ El-Etre et al. explained that the degree of inhibition depends on the nature of metal and the type of the medium. ${ }^{15}$ Several authors studied the corrosion inhibition of some plant extracts containing Linalool as active ingredient in their extracts. ${ }^{16-18}$

The aim of the present work is to compare the efficiency of Bitter orange, Citrus Aurantium (CA), extract and one of its chemical constituents, Linalool, on inhibiting the corrosion of mild steel in $0.5 \mathrm{~mol} \mathrm{~L}^{-1} \mathrm{HCl}$.

\section{EXPERIMENTAL}

\section{Solution preparation}

Linalool chemical compound (SigmaAldrich), analytical grade reagent $\mathrm{HCl}(\mathrm{BDH})$ and distilled water were used to prepare the test solutions. The test solutions were prepared from distilled water and analytical grade reagent $\mathrm{HCl}$ purchased from $\mathrm{BDH}$ chemical company and Linalool chemical compound.

*e-mail: ashrafmoustafa@yahoo.com;

\#alternative e-mail: a.abdelgaber@bau.edu.lb
A stock solution of CA extracts was obtained by drying the plant leaf for $2 \mathrm{~h}$ in oven at $80{ }^{\circ} \mathrm{C}$ and grinding to powdery form. $10 \mathrm{~g}$ sample of the powder was refluxed in $100 \mathrm{~mL}$ distilled water for $1 \mathrm{~h}$. The refluxed solution was filtered to remove any contamination. The concentration of the stock solution was determined by evaporating $10 \mathrm{~mL}$ of the filtrate and weighing the residue. The concentration of the stock solution was expressed in term of grams per liter. Prior each experiment, $4 \mathrm{~mol} \mathrm{~L}^{-1} \mathrm{HCl}$ is added to an appropriate volume of the stock solution of plant leaf extract and distilled water to obtain a solution of $0.5 \mathrm{~mol} \mathrm{~L}^{-1} \mathrm{HCl}$ solution and the required concentration of the extract. ${ }^{12}$

\section{Electrochemical studies}

Electrochemical impedance and polarization measurements were achieved using frequency response analyzer (FRA)/potentiostat supplied from ACM instruments (UK). The frequency range for electrochemical impedance spectroscopy (EIS) measurements was 0.1 to $3 \times 10^{4} \mathrm{~Hz}$ with an applied potential signal amplitude of $\pm 10 \mathrm{mV}$ around the rest potential. The data were obtained in an electrochemical cell of three-electrode mode; platinum wire and saturated calomel electrodes (SCE) were used as counter and reference electrodes. The material used for constructing the working electrode was mild steel of the following chemical composition (wt. \%) (C:0.198, Mn:0.57, Si:0.085, S:0.038, P:0.02, and Fe:98.8). Steel plate of rectangular shape was encapsulated in Teflon in such a way that only one surface was left uncovered. The exposed area $\left(0.36 \mathrm{~cm}^{2}\right)$ was mechanically abraded with a series of emery papers of variable grades, starting with a coarse one and proceeding in steps to the finest (800) grade. Polarization curve measurements were obtained at a scan rate of $30 \mathrm{mV} / \mathrm{min}$ starting from cathodic potential $\left(\mathrm{E}_{\text {corr }}-250 \mathrm{mV}\right)$ going to anodic direction. All the measurements were done at $30 \pm 0.1{ }^{\circ} \mathrm{C}$ using WiseCircu water bath (Germany) in solutions open to the atmosphere under unstirred conditions. To obtain the activation parameters the measurements were carried out at $30-60^{\circ} \mathrm{C}$. To test the reliability and reproducibility of the measurements, duplicate experiments were performed under the same conditions in each case and found to be within $2 \%$ error. 


\section{FTIR analysis}

The infrared spectra of the solid sample of CA were recorded by averaging 32 scans at a resolution of $4 \mathrm{~cm}^{-1}$ using a Perkin-Elmer (2000 FTIR) spectrometer in the spectral region between 4000 and $500 \mathrm{~cm}^{-1}$. The FTIR spectra of the samples that were solids were determined using a solid FTIR sample holder at Faculty of Engineering and Physical Sciences, University of Surrey (UK).

\section{AFM surface morphology}

The analysis of the morphology of the mild steel surface was carried out using atomic force microscopy (AFM), operated in the contact mode under ambient conditions using Agilent 5420 Atomic Force Microscope. Images of the specimens were recorded after $2 \mathrm{~h}$ of exposure in $0.5 \mathrm{~mol} \mathrm{~L}^{-1} \mathrm{HCl}$ without and with $0.6 \mathrm{~g} \mathrm{~L}^{-1}$ of CA leaf extract or Linalool at $25^{\circ} \mathrm{C}$. The probe has a maximum measuring area of $100 \times 100$ micrometer. AFM analysis was done at Lebanese University - Fanar Campus; Platform for Research in Nanosciences and Nanotechnologies.

\section{RESULTS AND DISCUSSION}

\section{Spectrophotometric analysis}

The Lebanese bitter orange called Citrus Aurantium (CA) is a source of many of chemical compositions. It has a high content of Linalool, Bergamol, Farnesol and D-Limonene. ${ }^{19}$ Figure 1(a, b) shows the IR spectra for CA leaf extract and Linalool. The IR spectrum of Linalool is from the NIST/EPA Gas-Phase Infrared Database..$^{20}$ These spectra display broad absorption band centered at $3300 \mathrm{~cm}^{-1}$ for CA leaf extract and at $3600 \mathrm{~cm}^{-1}$ for linalool which are attributed to alcohol $\mathrm{OH}$ stretch. The absorption bands in the region of $2917.8 \mathrm{~cm}^{-1}$ in CA spectrum and $2900-2950 \mathrm{~cm}^{-1}$ in linalool spectrum are assigned to the $\mathrm{C}-\mathrm{H}$ stretching vibrations. The strong bands in the region of 1033 in CA spectrum and $1090 \mathrm{~cm}^{-1}$ in linalool spectrum are assigned to the $\mathrm{O}$ - symmetric and asymmetric stretching vibrations and the $\mathrm{C}-\mathrm{O}$ stretching vibration. The percentage of Linalool in the hydro-distilled leaf extract was found by Azhdarzadeh et al. ${ }^{21}$ and by Trabelsi et al. ${ }^{22}$ to be 32.60 and 22.11, respectively.
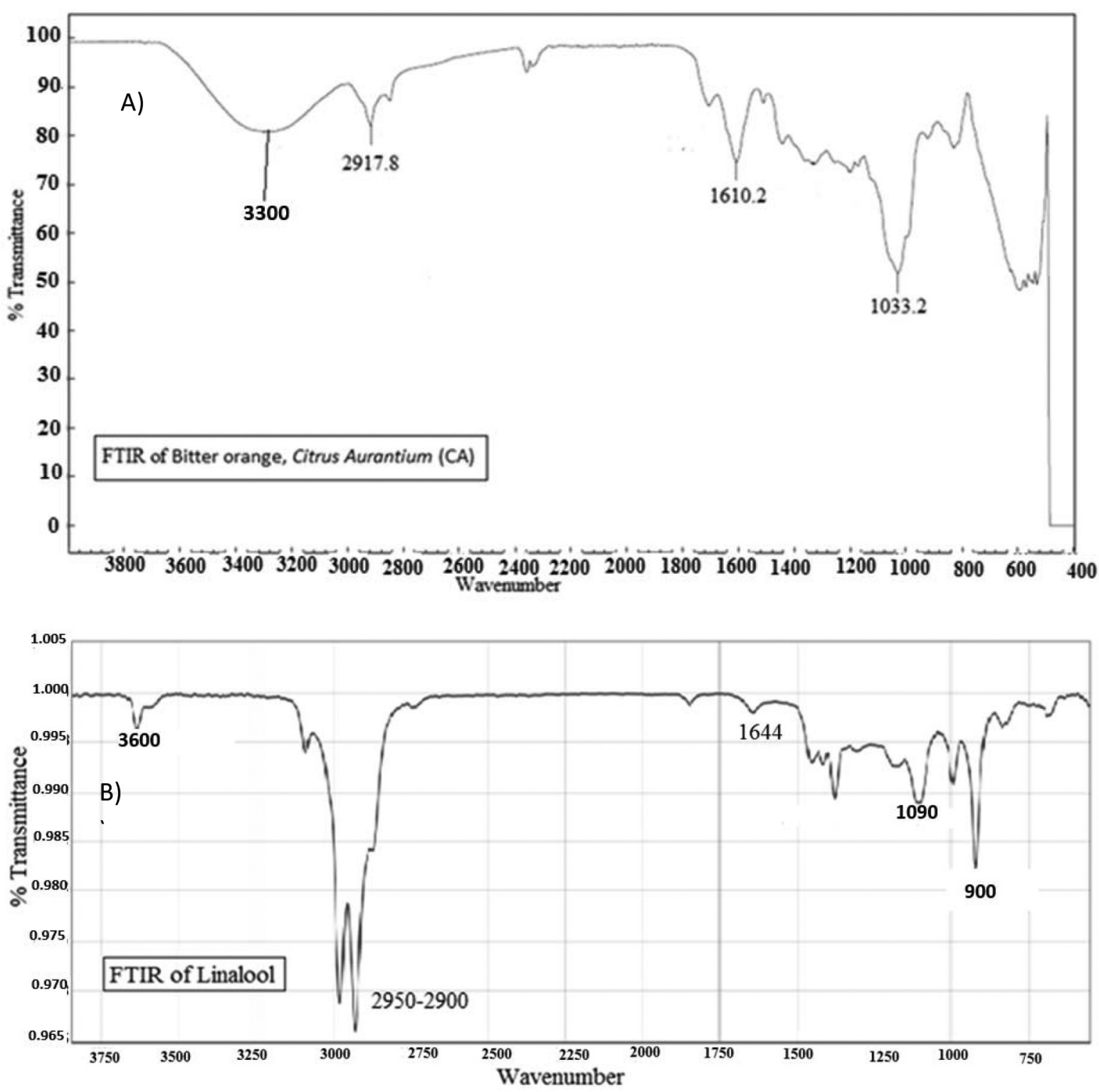

Figure 1. a) IR spectrum for Citrus Aurantium (CA) leaf extract; b) IR spectrum for Linalool 


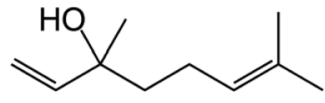

Figure 2. The chemical structure of Linalool

\section{Potentiodynamic polarization curves}

Before polarization and EIS measurements, the working electrode was left for $20 \mathrm{~min}$ to attain the open circuit potential in the used solution. The variation of the open circuit potential as a function of time for steel in $0.5 \mathrm{~mol} \mathrm{~L}^{-1} \mathrm{HCl}$ solution in the absence and presence of CA leaf extract and Linalool at $30^{\circ} \mathrm{C}$ is shown in Figure 3. As seen, a steady potential (open circuit potential $\mathrm{E}_{\mathrm{oc}}$ ) was readily attained after 20 minutes, corresponding to the free corrosion of the metal. The potential of steel was shifted to more noble direction on adding either Linalool or CA leaf extract.

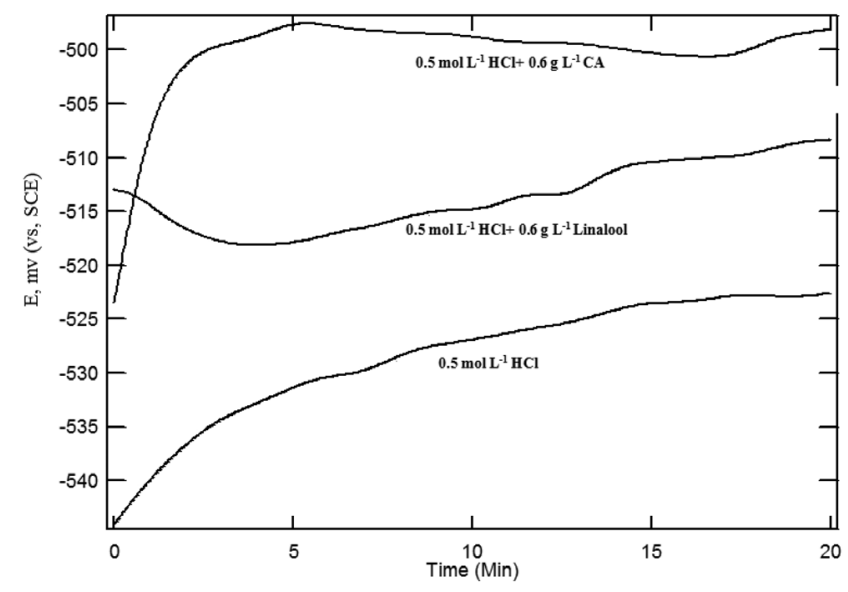

Figure 3. The variation of the open circuit potential as a function of time for steel in $0.5 \mathrm{~mol} \mathrm{~L}^{-1} \mathrm{HCl}$ solution in the absence and presence of CA leaf extract and Linalool at $30^{\circ} \mathrm{C}$

Figure 4 shows the potentiodynamic polarization curves of steel in $0.5 \mathrm{~mol} \mathrm{~L}^{-1} \mathrm{HCl}$ solution in the absence and the presence of $0.60 \mathrm{~g} \mathrm{~L}^{-1}$ of $\mathrm{CA}$ and Linalool. The figure indicates that both CA extract and Linalool retard the anodic and cathodic parts of the curves indicating that they act as mixed-type inhibitors. In general, for acid solutions, when dissolved oxygen is present, both hydrogen evolution and oxygen reduction reactions will be possible. However, the concentration of $\mathrm{H}_{3} \mathrm{O}^{+}$in acid solutions, at $\mathrm{pH} \approx 0$, is high, and since this ion has a high rate of diffusion. Consequently, the contribution made by the hydrogen evolution reaction on the cathodic process will predominant takes place by oxygen reduction reaction. The inhibitor may affect either the anodic or the cathodic reaction, or both. ${ }^{23}$ Therefore, CA and Linalool inhibit cathodic hydrogen evolution and anodic metal dissolution reactions. Since the anodic and cathodic Tafel lines slopes $\beta_{\mathrm{a}}$ and $\beta_{\mathrm{c}}$ of CA and Linalool were found to change slightly with inhibitor concentration, this indicates that CA leaf extract and Linalool inhibit the corrosion of mild steel surface through similar mechanism. ${ }^{24}$

The electrochemical polarization parameters together with percentage of inhibition efficiency, $\eta$, are given in Table1. $\eta$ was calculated from polarization measurements using the relation

$$
\eta=\left[\left(i_{0}-i\right) / i_{0}\right] \times 100
$$

where $i_{o}$ and $i$, are the corrosion current densities in the absence and the presence of plant leaf extracts and Linalool, respectively. ${ }^{14,25}$

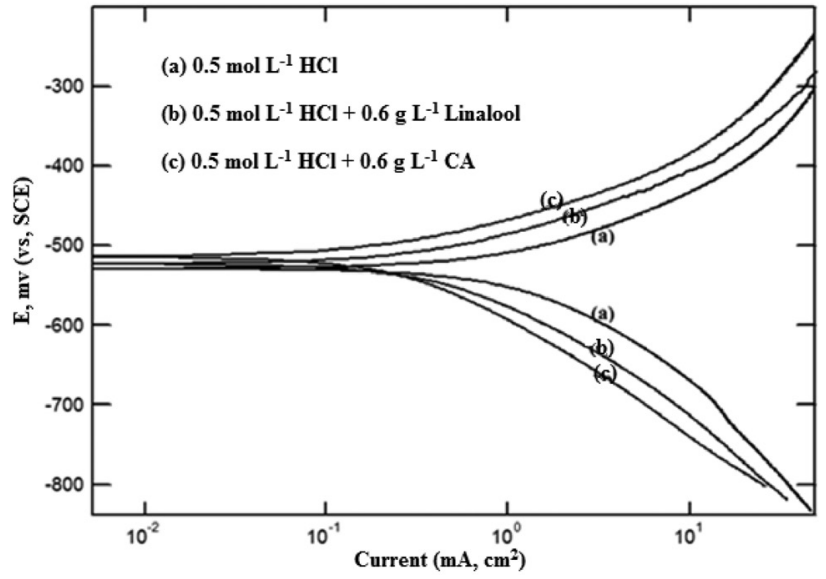

Figure 4. Potentiodynamic polarization curves of steel in $0.5 \mathrm{~mol} \mathrm{~L}^{-1} \mathrm{HCl}$ in the absence and presence of $0.6 \mathrm{~g} \mathrm{~L}^{-1}$ of Linalool and CA leaf extracts at $30^{\circ} \mathrm{C}$

The tabulated data indicate that the corrosion current density $\left(\mathrm{i}_{\text {corr }}\right)$ decreases with increasing CA leaf extract and Linalool concentrations while the percentage of inhibition efficiency $(\eta)$ increases. The $\eta$ values show that, at any given concentration, CA leaf extract is more efficient than its active chemical ingredient Linalool.

Figure 5 shows variations of degree of surface coverage $(\theta=$ $\eta / 100)$ with the CA leaf extract and Linalool concentrations in 0.5 mol $\mathrm{L}^{-1} \mathrm{HCl}$ solution. Usually the degree of surface coverage depends on many factors including the active area or number of adsorption sites and their charge density, molecular size, mode of interaction with the metal surface and formation of metallic complexes. ${ }^{26}$ The plots indicate that degree of surface coverage increased with increasing the inhibitor concentration due to increase in the metal surface area covered by inhibitor molecules. At higher concentration, total blocking of active area taking place causing slight variation in the degree of surface coverage..$^{27}$ The curves also indicate that CA, at moderate concentrations region, is more effective than its chemical constituent Linalool in $\mathrm{HCl}$ solution.

\section{Electrochemical impedance spectroscopy measurements}

Figures 6 shows Nyquist impedance plots of steel in $0.5 \mathrm{~mol} \mathrm{~L}^{-1}$ $\mathrm{HCl}$ in the absence and the presence of $0.6 \mathrm{~g} \mathrm{~L}^{-1}$ of both CA leaf extract and Linalool. Figure 6 shows type of depressed semicircles indicating that the corrosion process occurs under charge transfer control. The depressed capacitive loop is also ascribed to dispersion effects, which have been attributed to roughness and inhomogeneities on the surface during corrosion. ${ }^{28,29}$ In inhibitor-free solution, only one depressed capacitive loop can be observed and that can be attributed to the time constant of the charge transfer and the double layer capacitance.

The impedance spectra for different Nyquist impedance plots were analyzed by fitting the experimental data to a simple equivalent circuit model, Figure $7 .{ }^{30}$

The constant phase element (CPE) is defined by two values, the non-ideal double layer capacitance $\left(\mathrm{Q}_{\mathrm{dl}}\right)$ and constant $(\mathrm{n})$. The percentage inhibition efficiency $(\eta)$ can be calculated from impedance measurements according to the equation: ${ }^{30}$

$$
\eta=\left[\left(R_{c t}-R_{c t 0}\right)\right] / R_{c t} \times 100
$$

where $\mathrm{R}_{\mathrm{ct} 0}$ and $\mathrm{R}_{\mathrm{ct}}$ are the values of the charge transfer resistance $\left(\Omega \mathrm{cm}^{2}\right)$ in the absence and the presence of leaf extract, respectively.

The values of electrochemical impedance parameters obtained from fitting the experimental data of steel in $0.5 \mathrm{~mol} \mathrm{~L}^{-1} \mathrm{HCl}$ 
Table 1. The electrochemical polarization parameters for the corrosion of steel in $0.5 \mathrm{~mol} \mathrm{~L}^{-1} \mathrm{HCl}$ in the absence and presence of different concentrations of CA leaf extract and Linalool at $30^{\circ} \mathrm{C}$

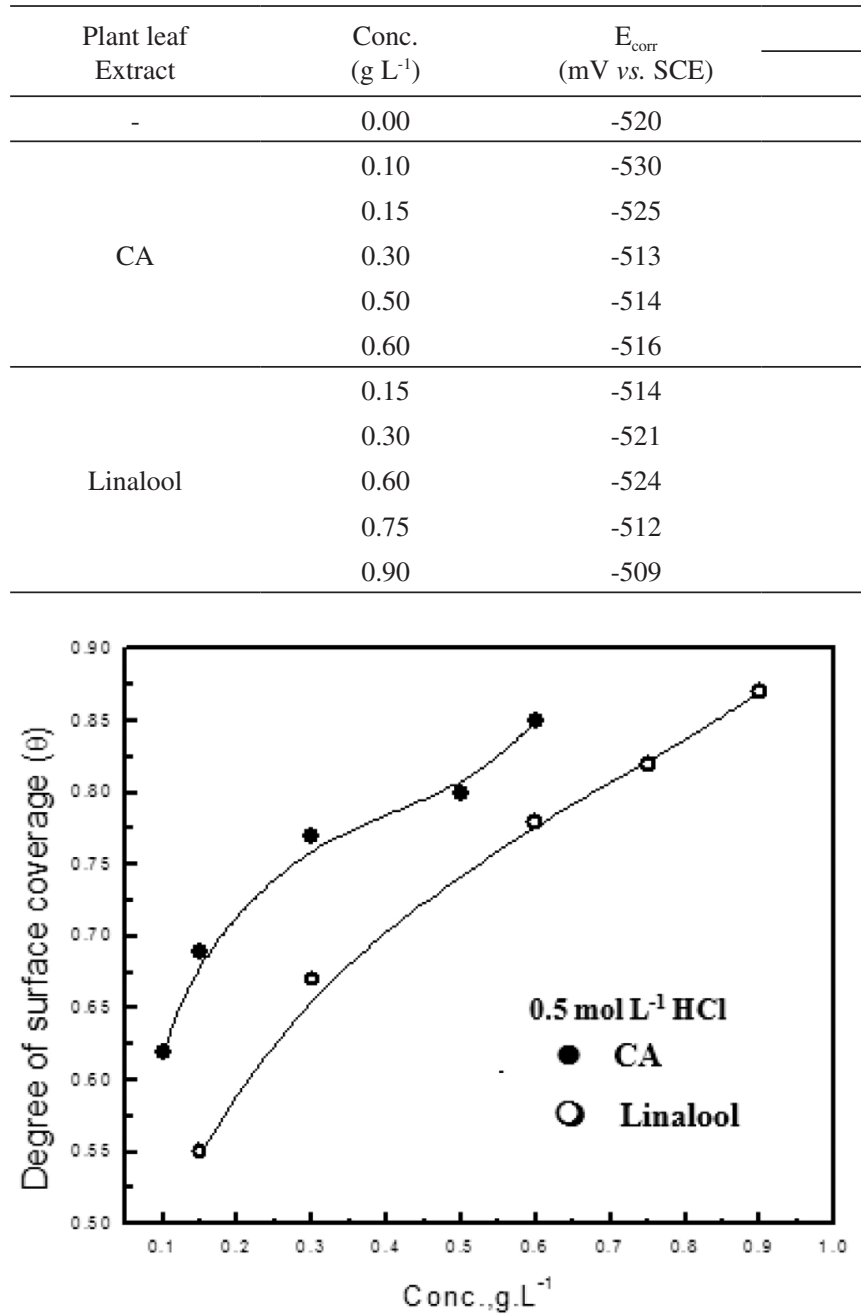

Figure 5. Variations of degree of surface coverage, obtained from polarization measurements, with the CA leaf extract and Linalool concentrations

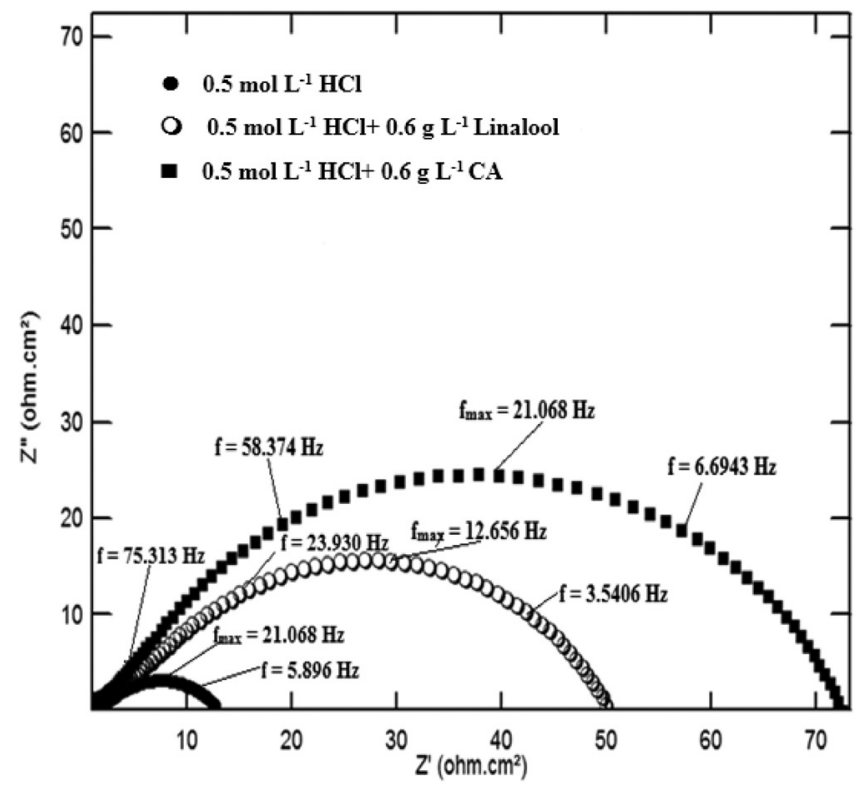

Figure 6. Nyquist plots for mild steel in $0.5 \mathrm{~mol} \mathrm{~L}^{-1} \mathrm{HCl}$ in the absence and presence of $0.6 \mathrm{~g} \mathrm{~L}^{-1}$ of both $\mathrm{CA}$ and Linalool at $30^{\circ} \mathrm{C}$

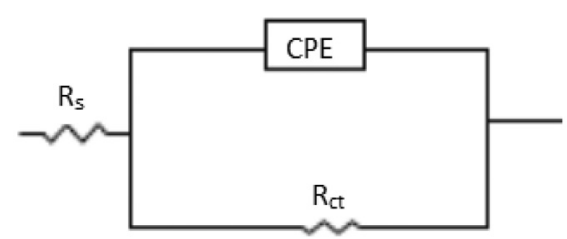

Figure 7. Schematic for the equivalent circuit model

solution containing different concentrations of CA leaf extract and Linalool to the used equivalent model are presented in Tables 2. Increasing $R_{c t}$ values in presence of CA and Linalool is due to the replacement of $\mathrm{H}_{2} \mathrm{O}$ molecules by organic molecules at the metal surface, decreasing the extent of the metal dissolution. ${ }^{31}$ The electrical double layer capacitance varies as function of dielectric constant, compact layer thickness, electrode size, and electrolyte concentration. Due to the fact that CA extract contains huge amount of chemical constituents, the increase of $\mathrm{Q}_{\mathrm{dl}}$ values in its presence could be attributed to increasing dielectrics. There are two types of dielectrics. The first type is polar dielectrics for polar molecules. The second type of dielectrics is the non-polar dielectrics for molecules that do not possess permanent electric dipole moment but can be induced by placing the molecules in an externally applied electric field. On the other hand, the decrease in $\mathrm{Q}_{\mathrm{dl}}$ in the presence of Linalool is due to the formation of an adherent film that increases the double layer thickness. It is also clear that the value of $Q_{\mathrm{dl}}$ decreased upon the addition of each of the inhibitors, indicating a decrease in the local dielectric constant and/or an increase in the thickness of the electric double layer. This indicates that the CA

Table 2. The electrochemical impedance parameters for the corrosion of mild steel in $0.5 \mathrm{~mol} \mathrm{~L}^{-1} \mathrm{HCl}$ in absence and presence of different concentrations of CA leaf extract and Linalool

\begin{tabular}{lccccc}
\hline Inhibitor & $\begin{array}{c}\text { Conc. } \\
\left(\mathrm{g} \mathrm{L}^{1}\right)\end{array}$ & $\begin{array}{c}\mathrm{R}_{\mathrm{ct}} \\
\left(\Omega \mathrm{cm}^{2}\right)\end{array}$ & $\begin{array}{c}\mathrm{Q}_{\mathrm{dl}} \\
(\mu \mathrm{F})\end{array}$ & $\mathrm{n}$ & $\eta$ \\
\hline- & 0 & 10.67 & 212 & 0.75 & - \\
\hline \multirow{3}{*}{$\mathrm{CA}$} & 0.15 & 31.86 & 747 & 0.78 & 67 \\
& 0.30 & 43.79 & 757 & 0.84 & 76 \\
& 0.60 & 73.32 & 773 & 0.80 & 85 \\
\hline \multirow{3}{*}{ Linalool } & 0.15 & 23.12 & 107 & 0.68 & 54 \\
& 0.30 & 33.91 & 128 & 0.69 & 69 \\
& 0.60 & 49.55 & 172 & 0.66 & 78 \\
\hline
\end{tabular}


extracts and Linalool inhibits the corrosion of steel in hydrochloric acid solution by the adsorption on the metal/electrolyte interface. ${ }^{32}$

\section{AFM surface morphology}

The surface morphologies of mild steel specimens immersed in $0.5 \mathrm{~mol} \mathrm{~L}^{-1} \mathrm{HCl}$ in the absence and the presence of CA leaf extract and Linalool were studied using atomic force microscope (AFM). AFM is ideally suited for characterization of the surface roughness of the metal specimens on micro scale..$^{33,34}$ The 3D images obtained before and after 2 hours of immersion are presented in Figure 8(a-d). It is observed that the steel surface in $0.5 \mathrm{~mol} \mathrm{~L}^{-1} \mathrm{HCl}$ solution is very rough. This rough surface is due to the rapid corrosion of the mild steel in $0.5 \mathrm{~mol} \mathrm{~L}^{-1} \mathrm{HCl}$ solution. However, in the presence of CA and the Linalool, the mild steel surface roughness was significantly reduced indicating the inhibiting action of both additives. The reduction in the surface roughness of mild steel coupons in the presence of CA compared to the Linalool confirms that leaf extract of CA is a better corrosion inhibitor than that of its chemical constituent, Linalool. The surface morphology results are in agreement with the results obtained from electrochemical impedance spectroscopy and polarization curves measurements and points to the existence of good inhibiting action of CA leaf extract and Linalool.

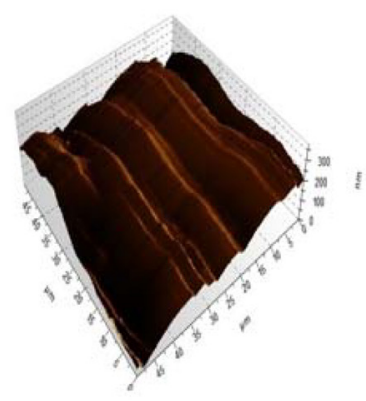

(a)

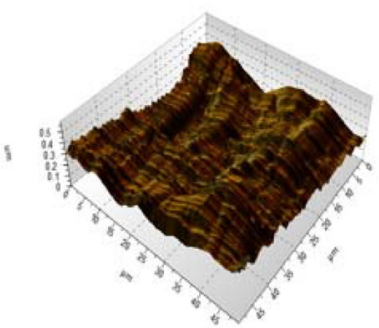

(c)

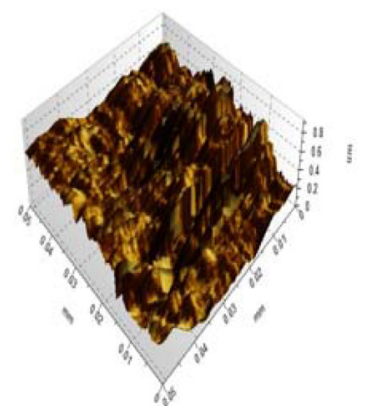

(b)

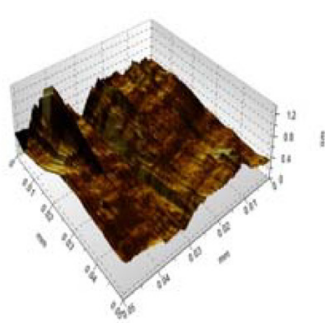

(d)
Figure 8. Three-dimensional AFM images for steel before immersion in (a) $0.5 \mathrm{M} \mathrm{HCl}$, and after immersion in (b) $0.5 \mathrm{~mol} \mathrm{~L}^{-1} \mathrm{HCl}$, (c) $0.5 \mathrm{~mol} \mathrm{~L}^{-1} \mathrm{HCl}$

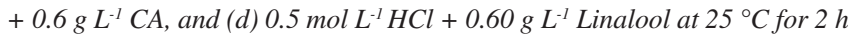

\section{Adsorption considerations}

Fitting experimental data in presence of inhibitor to the adsorption isotherms can give an insight to the adsorption mechanism. ${ }^{35}$ Attempts were made to fit the degree of surface coverage $(\theta=\eta / 100)$ values obtained from polarization curves measurements to the thermodynamic-kinetic model and FlorryHuggins isotherm.

Flory-Huggins isotherm is given by: ${ }^{36}$

$$
\log (\theta / C)=\log K+x \log (1-\theta)
$$

" $\mathrm{x}$ " is the size parameter and is a measure of the number of adsorbed water molecules substituted by a given inhibitor molecule.

The Kinetic - Thermodynamic model that is given by: ${ }^{37}$

$$
\log [\theta /(1-\theta)]=\log \mathrm{K}^{\prime}+\mathrm{y} \log \mathrm{C}
$$

where "y" is the number of inhibitor molecules occupying one active site; in other words, " $1 / \mathrm{y}$ " is the number of surface active sites occupied by one inhibitor molecule. The binding constant $\mathrm{K}$ is given by:

$$
\mathrm{K}=\mathrm{K}^{\prime}(1 / \mathrm{y})
$$

The parameters obtained from linear fitting of the mentioned model and isotherm, with correlation coefficients of 0.98 , for CA leaf extract and Linalool in $0.5 \mathrm{~mol} \mathrm{~L}^{-1} \mathrm{HCl}$ at $30{ }^{\circ} \mathrm{C}$ are depicted in Table 3.

Table 3. Linear fitting parameters of $\mathrm{CA}$ leaf extract and Linalool according to the Kinetic model and Flory-Huggins isotherm in $0.5 \mathrm{~mol} \mathrm{~L}^{-1} \mathrm{HCl}$ at $30^{\circ} \mathrm{C}$

\begin{tabular}{lcccccc}
\hline \multirow{2}{*}{ Inhibitor } & \multicolumn{3}{c}{ Kinetic Model } & \multicolumn{3}{c}{ Florry-Huggins } \\
\cline { 2 - 7 } & $\mathrm{K}$ & $1 / \mathrm{y}$ & $\mathrm{R}^{2}$ & $\mathrm{~K}$ & $\mathrm{x}$ & $\mathrm{R}^{2}$ \\
\hline CA & 22.28 & 1.64 & 0.99 & 19.89 & 1.86 & 0.98 \\
Linalool & 7.46 & 1.42 & 0.98 & 6.99 & 1.31 & 0.98 \\
\hline
\end{tabular}

The adsorption parameters obtained from linear fitting of Kineticthermodynamics models for $C A$ leaf extract and Linalool in $0.5 \mathrm{M}$ $\mathrm{HCl}$ at $30^{\circ} \mathrm{C}$ indicates that: (i) the molecules of CA leaf extract and Linalool occupy more than one active site since the values of the number of active sites occupied by a single molecule $1 / y$ are greater than unity (ii) the binding constant K, obtained from the kineticthermodynamic model, gives an indication for the strength of the interaction between these active ingredients and the metal surface. Large values mean better and stronger interaction, whereas small values of $\mathrm{K}$ of Linalool mean that the interaction between the active ingredients and the metal is weak. The values of $\mathrm{x}$ greater than unity indicate that both CA leaf extract and Linalool are bulky molecules. Therefore, the values of $1 / y$ and $x$ suggested that the bulky adsorbed molecule can cover more than one active site and displace more than one $\mathrm{H}_{2} \mathrm{O}$ molecule. . $^{38,39}$

\section{Effect of temperature}

Figures $9(a-b)$ show the polarization curves for steel in the absence and presence of $0.6 \mathrm{~g} \mathrm{~L}^{-1} \mathrm{CA}$ leaf extract and Linalool in $0.5 \mathrm{~mol} \mathrm{~L}^{-1} \mathrm{HCl}$ at different temperature respectively.

It is apparent from figures $9(a-b)$ that increasing temperature affect both anodic and cathodic part of the polarization curves. This behavior is attributed to increase of desorption of the inhibitor from the steel surface with rising temperature. ${ }^{40}$

On the other hand, Figure 10 shows Nyquist Impedance plots for mild steel in $0.5 \mathrm{M} \mathrm{HCl}$ in the presence of $0.60 \mathrm{~g} \mathrm{~L}^{-1} \mathrm{CA}$ leaf extract at different temperatures. It is clearly seen that increasing temperature decreases the size of the depressed semicircles indicating a decrease of the charge transfer resistance.

Some information on the mechanism of the inhibive action can be obtained by comparing apparent activation energy (Ea), obtained in the presence of inhibitor with that in its absence. The values of the thermodynamic parameters were determined using Arrhenius equation and transition state equation. ${ }^{41}$ As seen, the values of $\mathrm{E}_{\mathrm{a}}$ and $\Delta \mathrm{H}^{*}$ in the presence of the CA extract and Linalool are higher 

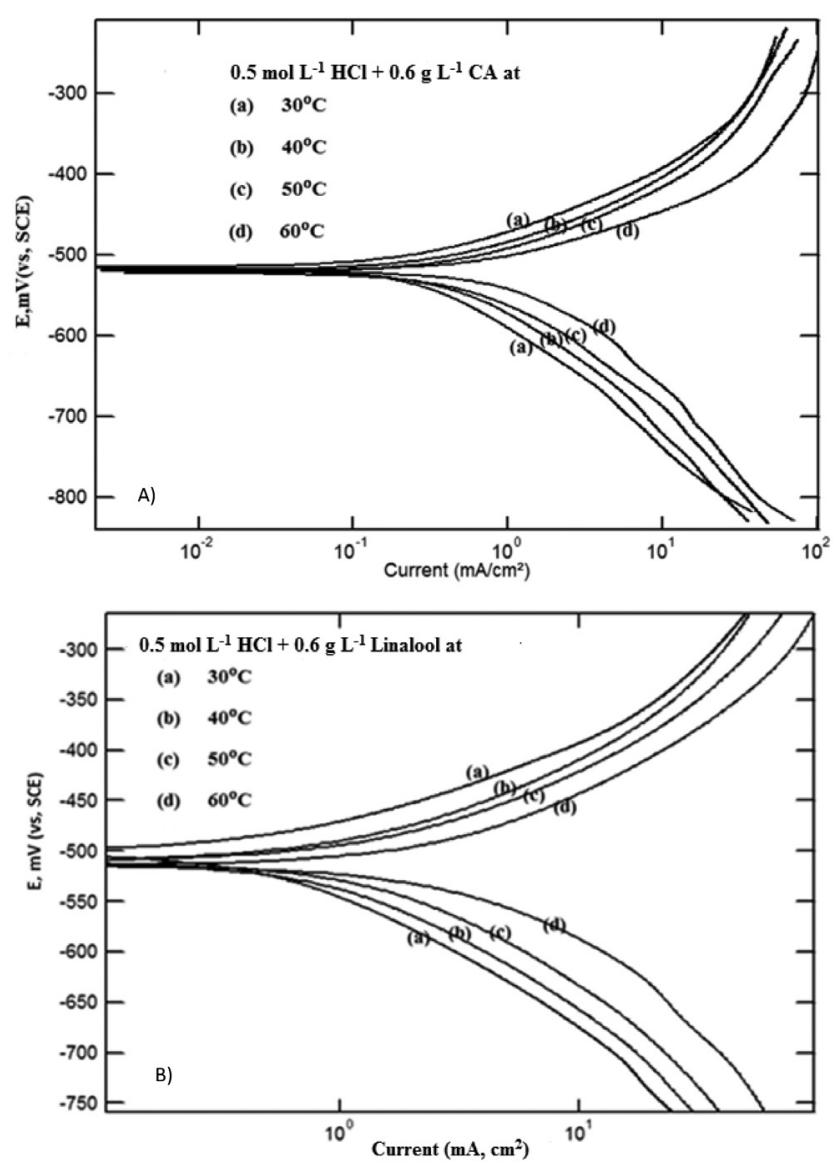

Figure 9. Potentiodynamic polarization curves for mild steel in $0.5 \mathrm{~mol} \mathrm{~L}^{-1}$

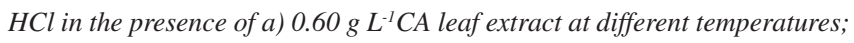
b) $0.6 \mathrm{~g} \mathrm{~L}^{-1}$ Linalool at different temperatures

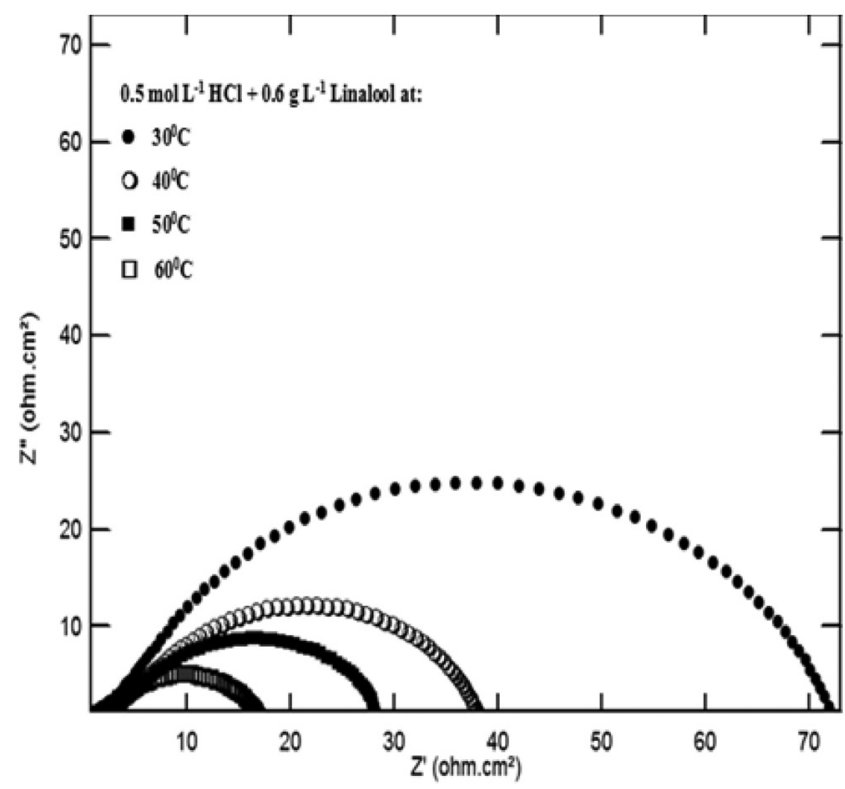

Figure 10. Nyquist Impedance plots for mild steel in $0.5 \mathrm{~mol} \mathrm{~L}^{-1} \mathrm{HCl}$ in the presence of $0.60 \mathrm{~g} \mathrm{~L}^{-1} \mathrm{CA}$ leaf extract at different temperatures

than that in their absence indicating geometric blocking effect of adsorbed chemical species. ${ }^{42}$ In addition, the average difference values of the $\left(\mathrm{E}_{\mathrm{a}}-\Delta \mathrm{H}^{*}\right)$ for CA and Linalool are 2.64 and $2.63 \mathrm{~kJ} \mathrm{~mol}^{-1}$, respectively which are approximately equal to the average value of RT $\left(2.63 \mathrm{~kJ} \mathrm{~mol}^{-1}\right)$ at $30^{\circ} \mathrm{C}$. This indicates that the corrosion process is a unimolecular reaction as it is characterized by the following equation: ${ }^{43}$

$$
\mathrm{Ea}-\Delta \mathrm{H}^{*}=\mathrm{RT}
$$

Table 4. The activation parameters of mild steel in $0.5 \mathrm{~mol} \mathrm{~L}^{-1} \mathrm{HCl}$ in the absence and presence of $0.6 \mathrm{~g} \mathrm{~L}^{-1} \mathrm{CA}$ leaf Extracts and Linalool respectively

\begin{tabular}{lcccc}
\hline Acid Solution & Inhibitor & $\begin{array}{c}\mathrm{E}_{\mathrm{a}} \\
\left(\mathrm{kJ} \mathrm{mol}^{-1}\right)\end{array}$ & $\begin{array}{c}\Delta \mathrm{H}^{*} \\
\left(\mathrm{~kJ} \mathrm{~mol}^{-1}\right)\end{array}$ & $\begin{array}{c}\Delta \mathrm{S}^{*} \\
\left(\mathrm{~J} \mathrm{~mol}^{-1} \mathrm{~K}^{-1}\right)\end{array}$ \\
\hline $0.5 \mathrm{~mol} \mathrm{~L}^{-1} \mathrm{HCl}$ & - & 31.79 & 29.16 & -172.59 \\
& $\mathrm{CA}$ & 37.88 & 35.24 & -163.91 \\
& Linalool & 50.73 & 48.10 & -121.85 \\
\hline
\end{tabular}

The endothermic nature of transition to the activated state is explained by the positive values of $\Delta \mathrm{H}^{*}$. In addition, the activated state represents an association state that is clarified from the negative value of $\Delta S^{*}{ }^{44-46}$ Therefore, the obtained data indicate that the adsorption of CA leaf extract and Linalool on metal surface takes place by electrostatic interactions between the charged molecules and the metal.

\section{CONCLUSION}

The following conclusions can be drawn from the work:

Citrus Aurantium (CA) leaf extracts and Linalool retard the corrosion of mild steel in $0.5 \mathrm{~mol} \mathrm{~L}^{-1} \mathrm{HCl}$ solution. Linalool is not the responsible (or unique responsible) for the inhibitive action from CA leaf extract, since the inhibition efficiency of the CA leaf extract is higher comparing to its chemical constituent, Linalool, in all measurements. The higher inhibition efficiency of CA leaf extract is due to synergistic effect of the active chemical constituents.

\section{ACKNOWLEDGEMENT}

This work was supported by National Council for Scientific Research (CNRS) Lebanon, reference number (05-13-12).

\section{REFERENCES}

1. Abd El-Rehim, S. S.; Hassan, H. H.; Amin, M. A.; Mater. Chem. Phys. 2001, 70, 64.

2. Chaieb, E.; Bouyanzer, A.; Hammouti, B.; Benkaddour, M. ; Appl. Surf. Sci. 2005, 264, 199.

3. Solomon, M. M.; Umoren, S. A.; Udosoro, I. I.; Udoh, A. P.; Corros. Sci. 2010, 52, 1317.

4. El-Etre, A. Y.; Mater. Chem. Phys. 2008, 108, 278.

5. Torres V. V.; Amado R. S.; de Sá, C. F; Femandez, T. L.; da Silva Riehl, C. A.; Torres, A. G.; D’Elia, E.; Corros. Sci. 2011, 53, 2385.

6. Ameer, M. A.; Fekry, A. M.; Prog Org Coat. 2011, 71, 343.

7. El-Etre, A.Y.; Corros. Sci. 2003, 45, 2485.

8. Abdallah, M.; Corros, Sci. 2004, 46, 1981.

9. Satapathy, A. K.; Gunasekaran, G.; Sahoo, S. C.; Kumar, A.; Rodrigues, P. V.; Corros. Sci. 2009, 51, 2848.

10. da Rocha, J. C.; da Cunha Ponciano Gomes, J. A.; D'Elia, E.; Corros. Sci. 2010, 52, 2341.

11. Abdel-Gaber, A. M.; Abd-El-Nabey, B. A.; Khamis, E.; Abd-El-Khalek, D. E.; Desalination 2008, 230, 314.

12. Hijazi, K. M.; Abdel-Gaber, A. M.; Younes, G. O.; Int. J. Electrochem. Sci. 2015, 10, 4366.

13. Ellouze, I.; Abderrabba, M.; Sabaou, N.; Mathieu, F.; Lebrihi , A.; Bouajila, J.; J. Food Sci. 2012, 77, 73. 
14. Soltani, N.; Tavakkoli, N.; Khayatkashani, M.; Jalali, M. R.; Jalali, Mosavizade, A.; Corros. Sci., 2012, 62, 122.

15. El-Etre, A. Y; Abdallah, M.; El-Tantawy, Z. E.; Corros. Sci. 2005, 47, 385 .

16. Khamis, E.; Al-Andis, N.; Materialwiss. Werkstofftech. 2002, 33, 550.

17. Al-Mhyawi, S. R.; Afr. J. Pure Appl. Chem. 2014, 8, 9.

18. Fouda, S. A.; Rashwan, S. M.; Abo-Mosallam, H. A.; J. Korean Chem. Soc. 2014, 58, 25.

19. Ellouze, I.; Abderrabba, M.; Sabaou, N.; Mathieu , F.; Lebrihi , A.; Bouajila, J.; J. Food Sci. 2012, 77, 73.

20. http://webbook.nist.gov/chemistry, accessed December 2016.

21. Azhdarzadeh, F.; Hojjati M., Nutr. Food Sci. Res. 2016, 3, 43

22. Trabelsi, D.; Ammar, A. H.; Bouabdallah, F.; Zagrouba, F.; IOSRJESTFT 2014, 8, 18.

23. Junaedi, S.; Al-Amiery, A. A.; Kadihum, A.; Kadhum, A. H.; Mohamad, A.; Int. J. Mol. Sci. 2013, 14, 11915.

24. Zhang, J.; Gong, X. L.; Yu, H. H.; Du, M.; Corros. Sci. 2011, 53, 3324.

25. Amin, M. A.; Abd El Rehim, S. S.; Abdel-Fatah, H. T. M.; Corros. Sci. 2009, 51, 882 .

26. Goudarzi, N.; Peikari, M.; Zahiri, M. R.; Mousavi, H. R.; Arch. Metall. Mater. 2012, 57, 845.

27. Abd-El-Nabey, B. A.; Abdel-Gaber, A.M.; El. Said Ali, M.; Khamis, E., \& El-Housseiny, S.; Int. J. Electrochem. Sci. 2013, 8, 7124.

28. Ostovari, A.; Hoseinieh, S. M.; Peikari, M.; Shadizadeh, S. R.; Hashemi, S. J.; Corros. Sci. 2009, 51, 1935.

29. Reis, F. M.; de Melo, H. G.; Costa, I.; Electrochim. Acta 2006, 51, 1780.

30. Priya, A. R. S.; Muralidharam, V. S.; Subramania, A.; Corrosion (Houston, TX, U. S.) 2008, 64, 541.
31. Bentiss, F.; Lagrenee, M.; Traisnel, M.; Hornez; J. C.; Corros. Sci. 1999, 41, 789 .

32. Jackson, E.; Essien. K.E.; Obot, I. B.; Chem. Sin. 2016, 7, 16.

33. Popova, A.; Sokolova, E.; Raicheva, S.; Christov, M.; Corros. Sci. 2003, $45,33$.

34. Anbarasi, C. M.; Rajendran, S.; International Journal of Current Engineering and Technology 2013, 3, 2091.

35. Teng, H. H.; Dove, P. M.; Orme, C. A.; De Yoreo , J. J.; Science 1998, 282,724 .

36. Florry, P. J.; J. Chem. Phys. 1942, 10, 51.

37. El-Awady, Y.; Abd-El-Nabey, B. A.; Aziz, S. G.; J. Electrochem. Sci. 1992, 38, 2149.

38. Abd-El-Nabey, B. A.; Abdel-Gaber, A. M.; Elawady, G. Y.; ElHousseiny, S.; Int. J. Electrochem. Sci. 2012, 7, 7823.

39. Abdel-Gaber, A. M.; Masoud, M. S.; Khalil, E. A.; Shehata, E. E.; Corros. Sci. 2009, 51, 3021

40. Sethuraman, M. G.; Aishwarya, V.; Kamal, C.; Edison, T. J. I.; Arabian J. Chem. 2012, in press (doi:10.1016/j.arabjc.2012.10.013)

41. Li, X. H.; Deng, S. D.; Fu, H.; Corros. Sci. 2012, 62, 163.

42. Tebbji, K.; Faska, N.; Tounsi , A.; Oudda, H.; Benkaddour, M.; Hammouti, B.; Mater. Chem. Phys. 2007, 106, 260.

43. Laidler, K. J.; Reaction Kinetics, Pergamon Press: New York, 1963.

44. Khalifa, O. R.; Abdallah, M.; Port. Electrochim Acta 2011, 29, 47.

45. Cristofari, G.; Znini, M.; Majidi, L.; Bouyanzer, A.; Al-Deyab, S. S., Paolini, J.; Hammouti, B.; Costa, J.; Int. J. Electrochem. Sci. 2011, 6, 6699.

46. Ben Hmamou, D.; Salghi, R.; Zarrok, H.; Abdelkader, Z.; Hammouti, B.; El Hezzat, M.; Bouachrine, M.; Adv. Mater. Corros. 2012, 1, 36. 